\title{
Operational Mechanism of Digital Humanistic Crowdsourcing Project Based on Actor Network Theory
}

\author{
Xiaojuan XU \\ School of Management, Anhui \\ University \\ xxjksks@126.com \\ Cuicui Wang \\ School of Management, Hefei \\ University of Technology \\ qad68@126.com
}

\author{
Hui Gao \\ School of Management, Hefei \\ University of Technology \\ 545498814@qq.com \\ Wei Xu \\ Renmin University of China \\ weixu@ruc.edu.cn
}

\author{
Jianshan Sun \\ School of Management, Hefei \\ University of Technology \\ sunjs9413@hfut.edu.cn
}

\begin{abstract}
This article is to promote the development of digital humanity-related crowdsourcing projects based on actor network theory (ANT). A case study on "Shengxuanhuai Documents" from Shanghai Library is selected as our research object. The article employs qualitative research approach to investigate core concepts, namely Problematization, Obligatory Passage Point, Interestment, and Mobilisation involved in the underway of the digital humanity-related crowdsourcing project. This study conducts interviews with 32 respondents, including the 10 contractees and 22 users. The crowdsourcing actors in humanityrelated projects are mainly the organizers from public libraries, museums, archives, and other digital humanity institutions. Based on the project development documents and semi-structured interview data, we find that the main obstacles to prevent actors engaging in crowdsourcing projects include task guidance, user motivations, platform designs, and competition evaluations. The paper demonstrates the usefulness of ANT's concepts and explores the contribution of each ANT analytical concept.
\end{abstract}

Keywords: actor-network theory; digital humanities; crowdsourcing; User motivation; case study

\section{Introduction}

As a rising multi-subject concerned research field, digital humanism attracts more attention in recent years. However, constructing digital humanistic resources has many challenges such as huge research workload, scattered content involved, limited financial support and diverse requirements of the research backgrounds. Based on the concept of open innovation and group wisdom, crowdsourcing can help project managers get more efficient, more economical and better construction solutions (Howe, 2009; Poetz and Schreier, 2009). Crowdsourcing has been successfully employed in the areas of art, libraries, archives, museums, educational institutions. For example, the US Library of Congress used Flickr ${ }^{1}$ to invite users to tag and comment on photos. The StoryCorps project in the United States allowed people to record, share and preserve American history memories since 2003. There were more than 40,000 interviews and 80,000 participants taking part in this project. The National Library of Australia and the National Library of Finland employed the public to correct the textual information in historical newspapers. In order to help historians understand the sailing routes of ships during the First World War, the Public Science Alliance used the public handwriting to translate the weather record files in the Royal Navy warships. CADAL (University Digital Library International Cooperation Program) in China used user-oriented approach to describe poor books, revise book description information and journal pages. Furthermore, the project rewarded readers for global access to limited books based on user contributions. These digital humanistic projects have achieved good social repercussions, and provide an effective solution for the construction and development of digital humanistic resources. In term of interdisciplinary and cross-platform advantages, crowdsourcing has become an effective method to promote the vigorous development of the field of digital humanities.

However, the application of crowdsourcing in digital humanistic projects is still in its infancy. The exploration of crowdsourcing model must be preceded from different view of stakeholders, and the design and management of the digital humanistic model should be

\footnotetext{
1 www.fickr.com
} 
researched deeply in accordance with the problems and difficulties emerging in the activities and projects. At the same time, action research focuses more on generating research power from perceived practical problems, which is consistent with the "task-driven, goal-oriented" approach of crowdsourcing model. Besides, the research of digital humanism crowdsourcing is not only the exploration of technical dimension, but also the research on the development of the involved group. ANT gave us a theoretical lens for the analysis of the relationship between technology, brought by the project, and society, represented by local people (Díaz Andrade and Urquhart, 2010). Theories that explore the implications of the interactions between the social and technical integration are needed given that what makes information system (IS) unique is the social-tech integration (Bostrom et al., 2009, Hanseth et al., 2004). Studies (Bagozzi, 2007, Venkatesh et al., 2007, Orlikowski and Lacono, 2001) have been calling on a new theoretical perspective that will boost our understanding of the technology (Lee and Oh, 2006), as well as, how the technology can be implemented taking into accounts of their broader context (Silva, 2007, Schwarz and Chin, 2007). These have motivated the proliferation and application of ANT (Silva, 2007) in the area of IT adoption and implementation. According to Faraj et al. (2004) when people (human actors) come into a network; they come with their ideas, motives and intensions which they try to impose on the technology (non-human actor) they intend to develop and/or adopt. When the key actor - a competing actor that ensures that other accept its claims in technology adoption and development interests are not in line with other actors beliefs (Sarker et al., 2006), the opportunity, for successful development and/or adoption becomes limited and thus results to movement (back and forth) of actor (Sarkeret al., 2006).

From the theoretical perspective of Actor-Network, this study uses the four core concepts of Problematization, Obligatory Passage Point, Interestment and Mobilisation to conduct the research. Based on the case of "A series of Shanghai Library digital humanities projects" and interviews with participants, the paper systematically analyzes the actors and their influencing factors in the current digital humanistic crowdsourcing project. We put forward the corresponding countermeasures and suggestions for the existing problems and provide guidance for the development of digital humanistic projects.

\section{Literature review}

\subsection{Digital Humanities}

Digital Humanities is a new research field developed on the basis of Humanities Computing. As a new type of interdisciplinary research field which applies modern computer and network technology to traditional humanistic research and teaching, it was not until the hold of Modern Language Association (The Modern Language Association) in 2009 that digital humanities has become a hot issue, consequently with the relevant research literature increased significantly (Chen Jing, 2014).China's research on digital humanities began in 1999, but the literature has been increased since 2012. Chinese research topics are close to foreign research topics. However, There is still a gap between foreign countries in the quantity of literature, the depth of research and the discipline intersection of research (Dongzhenge,chenhuilan, 2015).

At present, the digital humanities literature is mainly concentrated in four aspects: (1) Interpretation of digital humanities connotation. Such as the famous Italian anthropologist Busa (2004) holds that the most important results of human computing is not to accelerate the research speed of traditional humanities, but to provide new research methods and research paradigm for traditional humanistic research; Schreibman (2008) affirms this interpretation and points out that the goal of digital humanities is to integrate modern information technology into traditional humanistic research and teaching processes, thereby fundamentally changing the acquisition, labeling, comparison, sampling, interpretation and expression of humanistic knowledge. Chinese scholar Wang Xiaoguang (2010) argues that digital humanities is a new realm of interdisciplinary research, which applied modern computer and network technology to the traditional humanities research and teaching filed. (2) Related technology exploration of digital humanistic application. The research mainly includes the application of text mining, GIS technology, text visualization and semantic analysis in digital humanities (Kirschenbaum, 2007; Benito et al., 2015). And researchers are mostly from the field of computer and information science. (3) Exploration of digital humanities project and digital humanistic center construction. For more than a decade, more and more specialized "digital humanities centers" have been set up in European and American countries such as the Humanities Computing Research Center at King's College London, the Digital Humanities Research Center at the University of Southern California, the Computer-Assisted Humanities Research Center at Stanford University and Stanford Humanities Laboratory, Science and Academic Information Research Center at University of Illinois and Kyoto 
Digital Literature Research Center at Japan's Ritsumeikan University. China's relatively famous digital humanities centers include: "Digital Humanities Research Center of National Taiwan University", "Digital Humanities Center of Wuhan University" and "Cultural Heritage Inheritance and Digital Protection Collaborative Innovation Center" jointly established by Sun Yat-sen University and Central China Normal University, Quantitative History Institute of Peking University and so on. At the same time, the research project of digital humanities has been carried out in many fields such as literature, history (quantitative history), art, geography and so on. The famous projects include: The MONK project, Zotero, JSTOR, MARKUS, Database (CBDB) and "digital Dunhuang" project. At the same time, scholars at home and abroad have also explored the construction of digital humanities projects and digital humanities centers. For example, Anderson (2007) explores the historical geographic information system (historical GIS) which first transforms the historical map into data, with combination of the existing theories, and the paper applies computer software technology to the data analysis and processing, and finally displayed visually. Through the analysis of digital humanities in foreign archives, Zhao Shenghui et al.(2015) explore the development trend of digital humanities in the field of Chinese archives. In general, the Digital Humanities Center serves as an entity for the application of new media and new technologies to humanistic research and teaching, knowledge practice and experimentation (Zorich, 2008). The goal of Digital Humanities Center is to promote the development of humanities, to create new forms of knowledge and to explore the influence of technology on humanistic subject. (4) Exploration of digital humanities in the library, institutions and user collaboration. The research of digital humanities has typical interdisciplinary and cooperative nature. The library plays an important role in the development of digital humanities. Through the adjustment of literature resources, the library provides corresponding development orientation and service support for digital humanities on the basis of analysis of development layout, source publication, subject direction, region, organization and research direction.(Sula, 2013; Kamada, 2010; Zhou Qian, 2015). Siemens (2011), McCarty (2012), and Warwick (2012) et.al explore the organization and user collaboration filed in details.

\subsection{Digital humanistic crowdsourcing}

The research results of the Digital humanistic crowdsourcing project appear in conference papers, open access journals and workshops discussions. For example, based on the existing 36 digital humanistic projects, Carletti et al. (2013) sum up the current crowdsourcing tasks issued by digital humanities organizations mainly focused on the need of people to integrate / enrich / reconfigure existing institutional resources and requirement of people to create / contribute new resources. People are mainly involved in correction and transcription, contextual filling, supplementary collection, classification, collaborative management, crowdfunding and so on. The paper finally points out that the design target of the crowdsourcing project, the number of people and the statistical factors of the people will affect the quality of the program of crowdsourcing projects. Ridge(2013) and Carletti(2013) explore the crowdsourcing-themed workshops to discuss the main work content of the users in the digital humanistic crowdsourcing projects, the categories of the crowdsourcing tasks, the digital content management, the public participation motivation, the user's knowledge exchange and soon. And from the perspective of the case summarize the success elements of crowdsourcing, but the research doesn't form a scientific research result. Rhee (2013), Carletti (2013) et al. and Koh (2014) mainly introduces the digital humanities crowdsourcing project, pointing out that people can decide the ranking of articles in the project by voting and vetting. Although Terras (2015) has included the results in the book of Companion to Digital Humanities, the research mainly depends on descriptive analysis, expounding the application of crowdsourcing in digital humanities.

It is not difficult to find that in recent years, scholars at home and abroad have recognized the importance of crowdsourcing to the construction of digital humanities projects. However, due to the very limited "paid" (mostly "voluntary") of digital humanistic task, the scale and extent of user participation is not ideal, and the development of research is limited. Therefore, there is no further exploration in the elements involved in the operation of digital humanities, and the existence of obstacles how to stimulate and soon. At present, more scholars are discussing business and entertainment crowdsourcing scenarios (e.g., Brabham, 2010; Hossain, 2012). In view of this, this paper introduces the theory of Actornetwork-theory (ANT), which can takes resources allocation that involves the different actors and the relevant influencing factors into account. The research also focuses on the social (user) and technical dimensions, and uses the open interview method to fully understand the operating mechanism of the current digital humanistic crowdsourcing projects then discuss its present situation and the problem. According to the framework of the actor network theory (ANT), the research breaks through the problem 
one by one and step by step solve the existing problems in sequence.

\section{Research design}

\subsection{Actor network theory}

Actor network theory (ANT) is proposed by the Paris School of Social Science knowledge (SSK), which Latour, Callon and Law scholars are the core scholars. The theory mainly describes the "heterogeneous actors" to establish and develop a network and sociological solutions of specific problems. By analyzing the interaction, linkages and influences between actors, and then explain the adoption, promotion and use of technology in the community or organization, This theory reference the theory of system science, sociology and management, and provides the methodological guidance for how to connect and expand the dualistic view of "technology society".This coincides with the design concept of digital humanistic crowdsourcing, not only concerned about the realization of technical dimensions, but also concerned about the behavior of the user in the process of participation. That is, taking both technology and society into account.

ANT has gained considerable attention in the IS field and many IS scholars have applied it in their work (Elbanna, 2007). Hanseth et al. (2004) point out that ANT may contribute to the IS field not only by means of its conceptual vocabulary, but also by inspiring various ANT case studies providing rich understanding of the design and use of technologies which is of huge significant for the IS field. Such as Afarikumah and Kwankam (2013) published in Science on the application of ANT in remote electronic medical project, the paper analyzes the remote medical operation mechanism and the existing problems. Besides, the research further explains that in the application of ANT in system or large-scale project research, it is necessary to base on the corresponding interview data and combine with the sociological analysis and graph theory of ANT, and then conceptualize the unstructured data in interviews, such as the involved actors, the relationship between actors, and the path of interest and obstacles. The development of the digital humanism package is a typical information system implementation process, the actornetwork-theory (ANT) can provide theoretical and research support for this research. ANT concepts have also been used to study the technology development and adoption. For example, Faraj et al. (2004) adopted the concepts of inscription, translation and framing to examine the evolution of web browsers; while one of the early views of ANT (Walsham, 1997) demonstrated how ANT had been used in IT development and infrastructure standards. Tatnall and Jerzy (2003) used the concept of translation to interpret what actually derives older people to adopt ICT. In a more recently study, Andrade and Urquhart (2010) drew on ANT (the process of translation) to explore the different stages of ICT aimed to help the development in the rural area of the Peruvian Andes. This study based on the core ideas of Latour and Callon et al., Which mainly use Scenario, Problematization, Obligatory Passage Point, Interestment, Mobilisation and other constructs(as shown in Figure 1).The constructs are explained as follows:

Scenario refers to tell participants what kind of network is needed and attract the attention of other participants through such a script. Problematization refers to identify the claims and objectives of specific knowledge, so that other actors to accept its definition of the problem; Obligatory Passage Point (OPP) is the difficulty and obstacle that must be ruled out during the construction of the actor network. Interestment and Mobilisation as two aspects of recruiting members, with the Interestment means that through strategies to make other people or objects are recruited into the network as members, and the way of Interestment is translation. That is, how to motivate the user's behavior to make others participate in the project; Mobilisation refers to the control of the behavior of the actors, so that the actor groups can be consistent. These core concepts are interpreted based on the actors and its relationship. The main theoretical concepts involved in ANT include satisfying heterogeneous actors, generalized symmetry, translation and forced passages. Heterogeneous actors refers to the network, including human and non-human actors, such as technology, organizational groups and ethics, is the network construction of all the factors play a role. Generalized symmetry refers to the connection and role of human actors and non-human actors in the same way in the network of actors, also known as the principle of equivalence (Fenwick and Edwards, 2010).

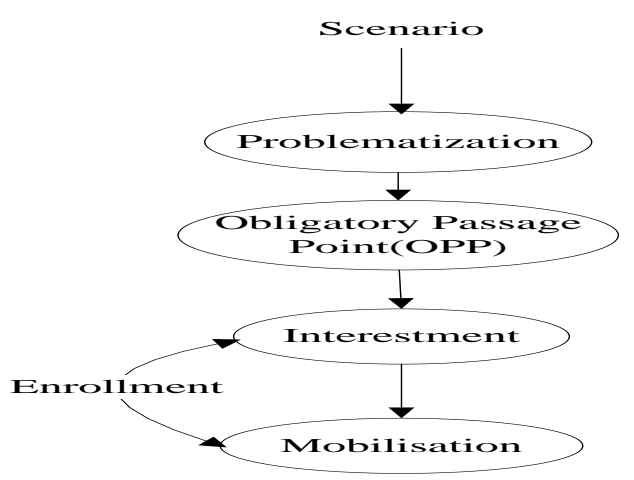




\section{Figure 1. The core concept of the actornetwork theory}

\subsection{Case selection}

As a public digital cultural research base of the Ministry of Culture, Shanghai Library is currently undertaking a series of digital humanities projects such as "Chinese genealogy", "Sheng Xuanhuai archives" knowledge base and so on. Digital human resources because of its particularity, there are still exist some difficult aspects to realize intelligent collection, integration and application through the computer, such as resource manual indexing, lack of collection resources, User perspective description requirement of characteristic resources construction and so on. And users under the tide of the Internet are also faced with sharing path of cognitive surplus and other issues. Based on this, Shanghai Library use crowdsourcing as a means of resource construction, and apply it into its resources building. In order to better carry out the digital humanistic crowdsourcing project, the core concept of the Actor Network Theory is introduced into this study. The data sources of this study are project development documents and semi-structured interviews. The former mainly comes from the documentary information involved in the construction of the project. The latter mainly generated by building the semi-structured problem which is based on the core conception of the actor network theory. The interview question is as follows:

Question 1: What actors do you often contract with and how do you describe the process when you participate in the "Chinese genealogy" or "Sheng Xuanhuai archives" project? What obstacles do you feel in the project's participation, what are the benefits for you and how to solve the above obstacles? (contractee)

Question 2: What actors do you often contract with and how do you describe the process when you participate in the "Chinese genealogy" or "Sheng Xuanhuai archives" project? What obstacles do you feel in the project's participation, what are the benefits for you and how to solve the above obstacles? (contractor)

This study uses the rooting theory to extract the interview and document data in a related manner and use analysis software Atlas.ti to analyze the data. The interview samples mainly from the contractee and the contractor (user) two dimensions, and use snowball sampling methods to obtain samples. There are a total of 32 users were interviewed, including 10 contractors, 22 users and 45-60 minutes for each user. The duration of the user's interview was 45-60 minutes, both sexes were half and demographic factors were under basic control.

\section{Data analysis}

On the purpose of finding out the main obstacles, interests, interestment and mobilisation in the operation of digital humanism and on the basis of defining the concept of the digital humanistic crowdsourcing project: Firstly, access to the core actors in the crowdsourcing network (as shown in 4.1). This study uses Bagozzi and Dabholkar (1994) the definition of truncation level methods to carry out the study. Due to the high level of interception may delete some of the necessary links and low interception level resulting in messy data, and the effect is not ideal, this paper by retaining the number of moderate actors, instead of more relationships, thus can achieve ideal results. Secondly, according to the acquired core actors, oriented analyze the content related to such actors of the interview material to define the problematization, Obligatory Passage Point, interestment, mobilisation and so on. As shown in 4.2 4.3.

At present the task requirements (problematization) issued by the digital humanities organizations are mainly concentrated in two dimensions:(1) integration, enrichment and reconfiguration of existing resources; (2) contribution and creation of new resources.

\subsection{The network of actors}

Based on the above-mentioned stage level definition method, the number of active cells was 5 when the number of cutoffs was 4 , and the remaining $32.21 \%$ of the living cells could cover $81.30 \%$ of the remaining activity relationship. That is, by using fewer activity units, instead of more relationships to achieve the desired results. In view of this, the number of core heterogeneous actors involved in the operation of the digital humanistic crowdsourcing is 5 , as shown in Table 1. The Contractee refers to the public library( or museum/archives), digital humanities institutions and other digital humanities project organizers; Digital humanistic crowdsourcing Contractor also called the user predominantly include ordinary users, experts, folk researchers and so on. The task generally means issues that need resolving in digital humanities. Such as the letter need to interpret in "Sheng Xuanhuai file", because the letter written as a traditional and Siamese and it is difficult to identify, so it is necessary to be resolved through the wisdom of the public; The platform generally is self-built or use third-party platform to publish the task. The current digital humanistic crowdsourcing organizers are relying on or 
embedded into the subordinate (secondary domain) of the organization. The characteristics of the two are as follows: Independent design of the crowdsourcing system is often less functional but targeted, but the R \& $\mathrm{D}$ expense is higher, and third-party platform crowdsourcing system has more function but sometimes "acclimatized"; The program refers to the results or answers of the digital humanistic crowdsourcing problems.

Table 1. The composition of heterogeneous actors

\begin{tabular}{|c|c|c|}
\hline & & \\
\hline Actors & Role & Main contents \\
\hline \multirow{10}{*}{$\begin{array}{l}\text { Human } \\
\text { Actors }\end{array}$} & Contractee & The Public Library / \\
\hline & & Museum / Archives, \\
\hline & & Digital Humanities \\
\hline & & Institutions and \\
\hline & & Other Digital \\
\hline & & Humanities Project \\
\hline & & Organizers; \\
\hline & Contractor & Ordinary Users, \\
\hline & & Experts, Folk \\
\hline & & Researchers \\
\hline \multirow{4}{*}{$\begin{array}{l}\text { Non- } \\
\text { Human } \\
\text { Actors }\end{array}$} & Task & Issues that Need \\
\hline & & Resolving \\
\hline & Platform & System \\
\hline & Scheme & Knowledge(Data) \\
\hline
\end{tabular}

To further combine the specific cases and the content of the interview, the network of the actors in this study, as shown in Figure 2. The digital humanities institutions, such as public libraries/museums and archives, will publish the task requirements on the platform, and the contractors (users) take the third party platform or the self-built platform of the contractor to undertake the corresponding tasks and give the scheme according to the task requirements. Digital human project organizers can rely on their own collection of user information, for the release of the project requirements to query the target users and then achieve online - offline two dimensions to lock the target users; According to the budget and project expansion and other factors, Digital humanities project organizers pre-assess whether to built platform by themselves. At present, the digital humanistic crowdsourcing project is the self-built platform provided by the organizers.

\subsection{Obligatory Passage Point design}

The data reliability analysis for the scope of the study shown in figure 3 revealed over $86 \%$. This suppressed the 70 percent benchmark suggested by Miles and Huberman (1994). Through the analysis of the case, the digital humanism class package is different from the general business model, the core actor's connotation has its own new characteristic: First of all, the mission object and solution quality assessment under the digital humanistic crowdsourcing environment is different from the previous commercial and entertainment scenarios; Second, the crowdsourcing user role in the context of public service has a new connotation: not only to complete the task on the platform, but also concerned about the growth of users and to meet the knowledge literacy promotion needs of more users; Finally, the solution to the crowdsourcing task reflects a strong situational dependency, and the crowdsourcing task under the digital humanities scenario is more inclined to allow users to "volunteer" to do things or services (organizers) want them to do things ( with very limited "paid"). In view of this, the Obligatory Passage Point of the digital humanistic crowdsourcing project is the principal (contractee) commissioned by a third party to build or the self-built task platform. The user's growth is achieved while the program is being obtained thus can pay attention on both "project and users". At the same time relying on the input of the program and with constantly improvement and modification of the resource library, which can formed a professional vertical type of knowledge base, and ultimately benefit for the user. What's more, in order to better analyze the implementation of Obligatory Passage Point process, the research combine with interviews and project

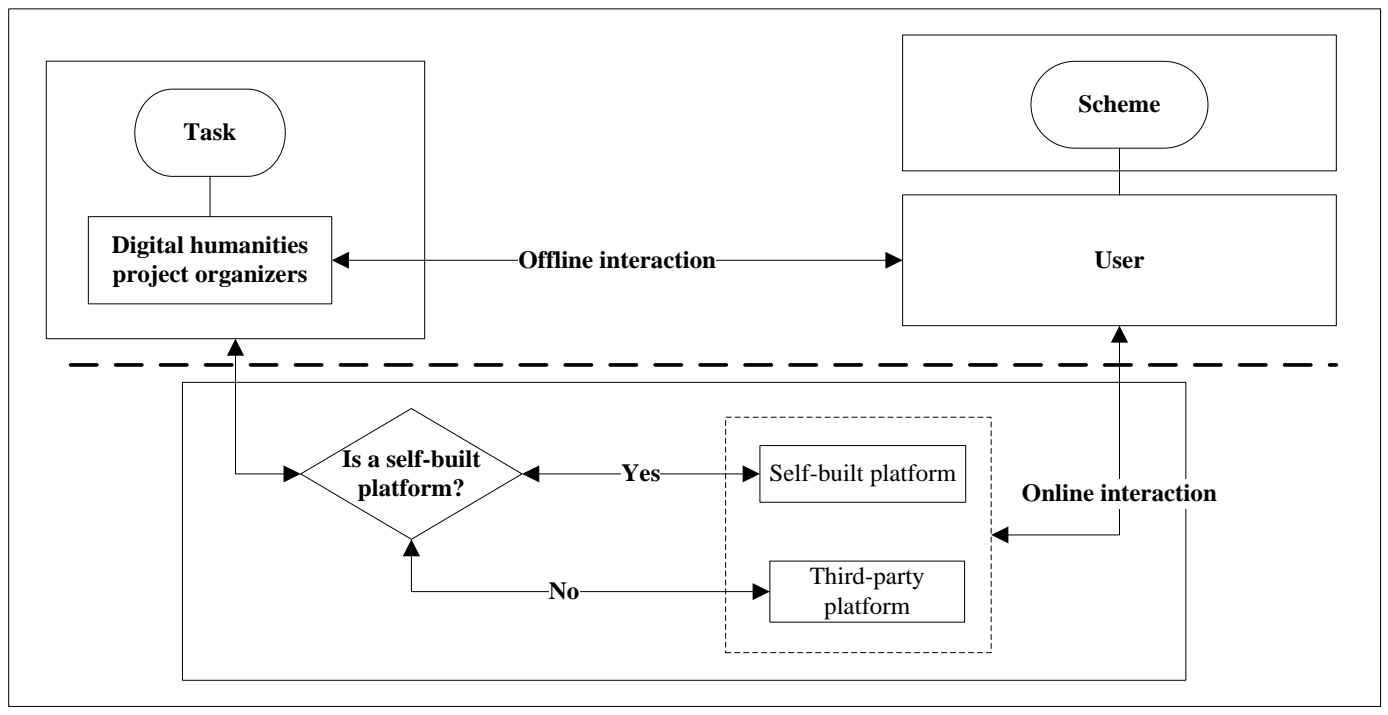

Page 319

Figure 2. Actors in the Digital Humanities Crowdsourcing and Their Mutual Relations 
development document material. Boyatzis (1998) identifies three methods of thematic analysis (datadriven approach, theory-driven approach and hybrid approach), we adopted theory-driven approach considering the fact that the concepts used in this study were initially derived from the existing theory (ANT). The obstacles and benefits involved in each of the actors are shown in Figure 3. difficult. Current funding is insufficient to find the authority and the knowledge of issued task is relatively for small minority.

Third, effect of task and the program. Interviewer Description: the quality and evaluation concerned by Digital humanities cannot be fully quantified. Explore the quality assessment control method that conforms to the humanistic system.

Forth, the assessment of expenditure overhead.

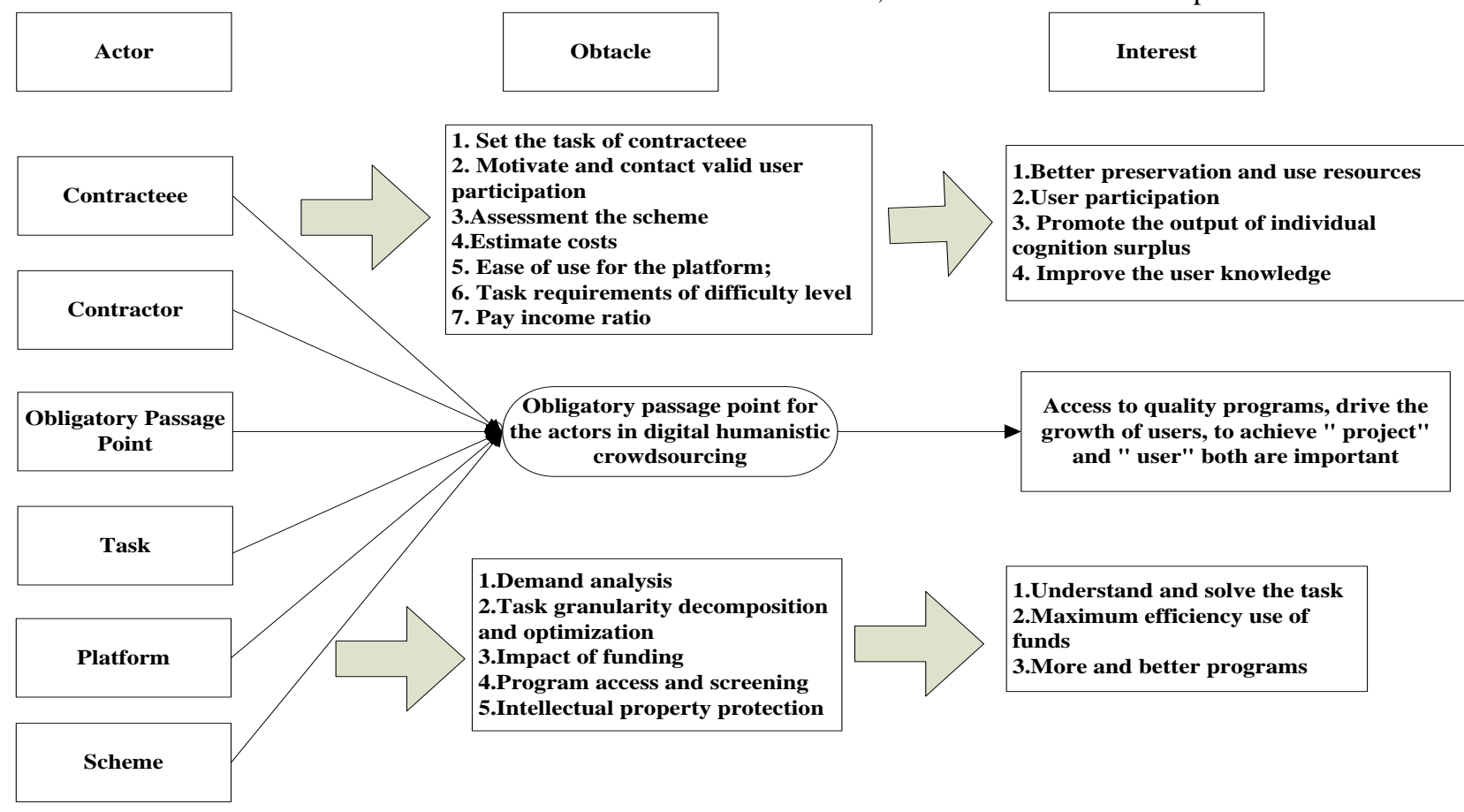

Figure 3. The barriers and benefits of digital humanities crowdsourcing

(1) Obstacles and benefits of human actors

As the organizer of the digital humanities project, the contractee runs through the whole process, and the influencing factors includes obstacles and the interests exist in all aspects. Obstacles associated with the contractee include four dimensions:

First, the task set of the contractee and the interviewer description: huge research workload of contractee, scattered content involved, limited support and the requirements of researchers' diverse subject background and other characteristics; There are some practical defects such as demand definition, scenario design, task granularity decomposition and optimization.

Second, encouragement and contact of "effective" user participation. Interviewer description: We lack a team in the platform design process, and cannot specifically verify the recommendations and feedback proposed by the user. What's more, we also don't know how to let the user spontaneously participate in our project; the discovery of the target user is also very interviewer description: how to choose the highest input-output ratio platform.

The interests of the contractee mainly from the resources and users: better organize, preserve and use resources; enhance public participation and drive the whole people to read and study to a certain extent.

As the producer, contractor is mainly composed of general user, expert, and folk researcher. There are three main obstacles items when find the task on the platform: accessibility of the platform, the difficulty of the task plan (high/low), and the benefits of efforts. The benefits are to promote the output of Individual cognition surplus with a view to self-satisfaction, in particular to promote the knowledge improvement of this "task" content attribute group.

(2) Obstacles and benefits of non-human actors

The obstacles or benefits of non-human actors are mapped to the resource (non-human actors) by the organizer, the developer, or the designer. For example, the daily use of child seats with "in order to better 
protect children's safety" interests, and these benefits are given by the designer.

First, the mission. The task obstacles mainly come from: first, conduct demand analysis of task application submitted by the contractor. Second, the task granularity decomposition and optimization .The benefit of the task is to allow users to understand and solve the task more efficient, so as to entering a better program.

Second, the platform. Platform barriers mainly from the building of platform is affected by funding. The program needs to measure the input and output ratio, and then decide to use self-built or third-party platform. The benefit lies in the maximum efficiency use of funds, and access to high quality solutions.

Third, the program. The obstacles of the program are: First, obtain large quantity and high quality programs to complete the knowledge base; Second, the protection of intellectual property rights, including whether user contributed knowledge is legitimate and reasonable in Pre-period and the latter part of the maintenance of property rights. The benefit lies in the access to more and better programs for the employer to filter.

\subsection{Interestment and Mobilisation}

According to the above obstacles and benefits, it is not difficult to find out: the requirements of the mission plan (task design and decomposition), user motivation (benefits of efforts), platform design (such as platform ease of use, expense assessment) and best program evaluation (program effect) are the factors that need to be stimulated urgently in the development of digital humanistic crowdsourcing. The purpose of Interestment and Mobilisation is to keep the actors behavior consistent and follows in the direction set by the target. Based on the interview material and project documentation, the research needs to carry out in the following four aspects:

First, the task level, From the external characteristics of the task, attributes, pre-knowledge requirements and the audience to conduct a comprehensive assessment to clarify the needs of the task, while based on different dimensions (such as difficulty, complexity and time cost) to classify the task, and combine with pre-test optimization task decomposition (how to solve) to subdivide task preferably.

Second, the motivational level, the current motivation mainly draws on the existing crowdsourcing research results of business scenarios, which can not completely solve the "voluntary" participation under digital humanistic crowdsourcing scenarios. Interviewers generally believe that the game should be introduced into the mechanism; the essence of the game is applying game elements to non-game scenarios and allows users to "volunteer" do what the product or service want them to do. This can effectively improve user participation, user viscosity and user loyalty (Deterding et al., 2011), with a high interest, and has positive impact on the user's education, learning and so on. In the process of solving the task, users personal knowledge, ability can be improved simultaneously and the corresponding game community can be formed. (Hamari et al., 2014). In the future, the digital humanistic crowdsourcing program should focus on the use of game mechanism.

Third, the platform design level. The platform of the digital humanities category package tend to start from a small and excellent self-built platform, and strive to make it bigger and stronger, but in different tasks the platform still need to conduct a specific assessment;

Fourth, the program level. The output of digital humanistic crowdsourcing program is different from the $\mathrm{Q} \&$ A community. the proposal (answer) have a certain degree of objectivity, so it can use qualitative (such as Wilson algorithm) and quantitative methods (such as peer review) to identify final high quality programs.

However, the study of Interestment and Mobilisation still needs to be further focused through practice. Under the background of the era of creating a generous culture, it is necessary to further enhance the research on the Interestment level. Making the behavior of the task, the contractor, the platform, the user and the program is mutually visible and form the alliance of interests for the common goal to complete "social production" which is from the task requirements to the program output of digital humanistic crowdsourcing.

\section{Discussion and implication}

This study applies the theory of the Actor-networktheory (ANT) to the digital humanistic crowdsourcing research. The paper analyzes the actors and influencing factors in the operation of the digital humanistic crowdsourcing project and also shows the fine-grained nature of the theory applied to the project. This helps to break through the problem one by one and step by step to solve the existing problems in sequence. The conclusions of this study are as follows:

First, the actor network of the digital humanities project is mainly composed of the task, the contractee (digital humanities project organizer), the platform (self-built or third-party platform), the user (contractor) and the program. The digital humanities institutions, 
which are headed by public libraries / museums and archives, publish tasks on the platform, and then the contractors (users) accept the tasks. The digital humanities organizations currently use the self-built platform to realize online-offline two dimensions user recruitment, then the contractor in accordance with the task requirements to submit a reasonable program.

Second, the obstacles and benefits. The requirements of the mission plan (task design and decomposition), user motivation (benefits of efforts), platform design (such as platform ease of use, expense assessment) and best program evaluation (program effect) are the main obstacle factors in the development of digital humanistic crowdsourcing. The interests of human activists mainly include: better organize, preserve and use resources; enhance public participation and drive the whole people to read and study to a certain extent; promote the output of Individual cognition surplus with a view to selfsatisfaction, in particular to promote the knowledge improvement of this "task" content attribute group. The interests of non-human actors are mainly given by the designer (the organizer).

Third, in the Interestment and Mobilisation level, the paper puts forward the corresponding framework, but the specific implementation still need further practice test. Researches need to be further carried out with a view to provide guidance for the orderly commencement of digital humanistic crowdsourcing project.

To provide improved recommendations for the developed platform, and to provide advice to developers who are currently preparing to develop the digital humanistic crowdsourcing platform. At present the task requirements (problematization) issued by the digital humanities organizations are mainly concentrated in two dimensions: first, integration, enrichment and reconfiguration of existing resources; second, contribution and creation of new resources.

\section{Acknowledgements}

This work is supported by National Social Science Youth Foundation in China (Grant No. 17CTQ001).

\section{References}

[1] Afarikumah E, Kwankam S Y. (2013).’Deploying actornetwork theory to analyse telemedicine implementation", in Ghana, 2nd (ed.), Science ,pp.77-84.

[2] Anderson M. M, A. ed., (2007). "“'Quantitative History” The Sage Handbook of Social Science Methodology", inLondon, 2nd (ed.), SagePublications,pp.246-263.
[3] Arthur T, Anthony G.(1999)."Actor-network theory and information systems research.",10th Australasian Conference on Information Systems, New Zealand: Wellington.

[4] Bagozzi R P, Dabholkar P A. (1994)."Consumer recycling goals and their effect on decisions to recycle: A means - end chain analysis",Psychology \& Marketing, Vol.11 No.4pp.313-340.

[5] Benito, G., Brázdil, R., Herget, J. and Machado, M. (2015). "Quantitative historical hydrology in Europe ",Hydrology and Earth System Sciences, Vol.19 No.8, pp.3517-3539.

[6] Busa R A.(2004)" A companion to digital humanitiesForeword: Perspectives on the digital humanities", Hoboken, New Jersey: John Wiley \& Sons,pp. 187-188.

[7] Cadal.zju.edu.cn. (2017). CADAL (CADAL Digital Library), available at: http://www.cadal.zju.edu.cn/index (Accessed 30 Mar. 2017).

[8] Chen, J. (2004), "History and Controversy - A Summary of the Development of British and American "Digital Humanities"', Culture Studies, Vol 2, pp.206-221.

[9] Callón M. (1986).”The sociology of an actor-network: the case of the electric vehicle ",Mapping the Dynamics of Science and Technology, Vol.20 No.1.pp.19-34.

[10] Callon M, Blackwell O. (2007).”Actor-Network Theory", The Politics of Interventions, pp.273-286.

[11] Carletti L, Giannachi G, Price D, et al. (2013)'Digital humanities and crowdsourcing: An exploration”, Museums and the Web.

[12] Díaz Andrade, A. and Urquhart, C. (2010). "The affordances of actor network theory", Information Technology \& People, 23(4), pp.352-374.

[13] Dong, E.L, Chen,H.L (2015), "Investigation and Development of Digital Human Resources", Information and Documentation Services, Vol 36 No 5, pp.103-109.

[14] Fenwick, T. Edwards, R. Actor-network theory in education [M]. Oxen: Routledge Press, 2010:2-70.

[15] Kamada H. (2010).'Digital humanities Roles for libraries?", College \& Research Libraries News, Vol.71 No.9,pp.484-485.

[16] Kirschenbaum M G. (2007).”The remaking of reading: Data mining and the digital humanities", The National Science Foundation Symposium on Next Generation of Data Mining and Cyber-Enabled Discovery for Innovation, Baltimore, MD. 
[17] Latour B. (1987)."Science in action: How to follow scientists and engineers through society", Harvard university press,pp.20-122.

[18] Law, J. (1984). "On the Methods of Long-Distance Control: Vessels, Navigation and the Portuguese Route to India", The Sociological Review, 32(1_suppl), pp.234-263.

[19] Loc.gov. (2017). Library of Congress Photos on Flickr (Prints and Photographs Reading Room, Library of Congress), available http://www.loc.gov/rr/print/flickr_pilot.html (Accessed 30 Mar. 2017).

[20] McCarty W.(2012),"Collaborative research in the digital humanities", Collaborative Research in the Digital Humanities,Vol.22 No.5,pp. 1-10.

[21] Poetz, M. and Schreier, M. (2012). "The Value of Crowdsourcing: Can Users Really Compete with Professionals in Generating New Product Ideas?", Journal of Product Innovation Management, Vol.29 No.2, pp.245-256.

[22] Sarker S, Sarker S. (2006).’Understanding business process change failure: An actor-network perspective", Journal of management information systems, Vol.23 No.1,pp. 51-86.

[23] Schreibman, Susan, Ray Siemens, and John Unsworth, et al. (2008),"A companion to digital humanities." Hoboken, New Jersey: John Wiley \& Sons.

[24] Science in action: How to follow scientists and engineers through society. (1987). In: Harvard university press, 3rd ed. pp.20-122.

[25] Siemens, L., Cunningham, R., Duff, W. and Warwick, C. (2011)."A tale of two cities: implications of the similarities and differences in collaborative approaches within the digital libraries and digital humanities communities", Literary and Linguistic Computing, Vol.26 No.3, pp.335-348.

[26] Sindlinger, T. (2010). "Crowdsourcing: Why the Power of the Crowd is Driving the Future of Business",American Journal of Health-System Pharmacy, Vol.67 No.18, pp.1565-1566.

[27] StoryCorps. (2017). StoryCorps,available at: https://storycorps.org/ (Accessed 30 Mar. 2017).

[28] Sula, C. (2013). "Digital Humanities and Libraries: A Conceptual Model", Journal of Library Administration, Vol.53 No.1, pp.10-26.

[29] Walsham G. (1997) ."Actor-network theory and IS research: current status and future prospects." New York: Springer US,pp.466-480.

[30] Wang,X.G (2010), The Emergence, Development and Frontier of "Digital Humanities", Wuhan University Press, WuHan.

[31] Warwick C. (2012)."Studying users in digital humanities “, Digital Humanities in Practice, Vol.17 No.5.pp.1-21.

[32] Zhao, S.H, Zhu,X.F (2014), "On the Construction of Digital Humanities Center in Chinese Universities", Library and Information Services, Vol. 58 No. 6, pp.6469.

[33] Zorich D. (2008) ."A survey of digital humanities centers in the United States. "Washington, DC: Council on Library and Information Resources.

[34] Zhou,Q. (2015), "University Library Service Innovation for Digital Humanities", Journal of Library Science, Vol. 37 No. 6, pp.92-94. 